\title{
Investigating the Wastes Management Practices of Businesses in Nigeria
}

\author{
Ebikapade Amasuomo ${ }^{1} \& \mathrm{Jim}_{\text {Baird }}{ }^{1}$ \\ ${ }^{1}$ School of Engineering and Built Environment, Glasgow Caledonian University, Glasgow, UK \\ Correspondence: Ebikapade Amasuomo, School of Engineering and Built Environment, Glasgow Caledonian \\ University, Glasgow, UK. E-mail: ebiyoko@yahoo.co.uk
}

Received: November 4, 2016

Accepted: November 21, 2016 Online Published: November 25, 2016

doi:10.5539/jms.v6n4p107

URL: http://dx.doi.org/10.5539/jms.v6n4p107

\begin{abstract}
Wastes and environmental management in many Nigerian cities have suffered tremendous setbacks in the last few decades. Literatures and environmental reports confirm a below average performance in relation to wastes and environmental management practices. Apart from unwholesome practices that characterises wastes management at household levels, many businesses across Nigeria have also capitalized on the lack of proper monitoring and enforcement of wastes and environmental laws to adopt practices that promotes organizational profits over environmental quality.

Hence, the current research investigates wastes management practices of small businesses (retailers) in Nigeria with a view to identify where corrections should be made in order to improve the overall wastes management standards in the country.

In order to achieve these aims and to proffer adequate solutions to the wastes management issues in the city, the paper employed a mixed method approach using closed and open-ended questionnaires in collecting data. In all about 900 questionnaires were collected and analysed for the study. A multi stage cluster sampling technique was employed due to the unavailability of an up-to-date sampling frame in the study area.

It was found that businesses were heavily involved in unfriendly environmental practices such as; burning of wastes, random and indiscriminate disposal, dumping of wastes on water bodies and disposal on illegal dumpsites. These wastes management practices were found to be a clear violation of standard international best practices as only a fraction of businesses dispose their wastes using official disposal points. The study therefore advocates that the wastes management authorities develop a means of influencing the environmental culture of organizations (retailers) in order to improve wastes management among businesses. Similarly, the research argues that adequate environmental policies be formulated and enforced in order to encourage retailers to embrace sustainable wastes management practices.
\end{abstract}

Keywords: Wastes management, environmental culture, wastes disposal, communal collection

\section{Introduction}

\subsection{Challenges Facing Household and Commercial Wastes Management}

Nigeria, like other developing countries has her own share of waste and waste management crisis. Adefemi \& Awokunmi (2009) reported that urban centres are experiencing an increased rate of environmental deterioration as a result of indiscriminate dumping of solid waste. Inefficient collection and unsafe disposal characterise waste management in Nigeria (Ogwueleka, 2009). The waste management crisis in the country is already visible and contributing to social, political and environmental costs (Izugbara \& Umoh, 2004).

For this research study, a distinction is drawn between commercial and domestic/household wastes. Commercial wastes in Nigeria are likely to be on a similar scale to household wastes. The drivers and motivational factors for Nigerian businesses to manage waste effectively are likely to be different from those of Nigerian householders. What became apparent during the early stage of this research is that, very little data exists for business waste in the country.

Several studies and information exist in respect to household wastes (Afon, 2007; Nabegu, 2010; Rahji \& Oloruntoba, 2009). The studies shows that wastes generated at home are gathered, stored and then disposed to communal collection points. Usually the wastes management agencies would then collect the wastes from 
communal points for the purpose of disposal to landfills where the wastes are spread, compacted and then covered up with earth. The wastes management agencies tend to put more emphasis on household wastes by setting up several communal collection points closer to residential areas. However, the management strategy adopted for household wastes have failed to deliver the desired goals (Uwadiegwu \& Chukwu, 2013). This is evident from the huge piles of rubbish overflowing in many communal collection points as the rate of generation have clearly surpassed the rate of evacuation (Abel, 2007; Afon \& Okewole, 2007)

On the other hand, businesses are often left to manage or dispose of their waste in the most convenient manner possible. Since businesses are mostly out to make profit, they therefore give very little attention to waste management or environmental protection. Consequently, indiscriminate dumping and burning of commercial wastes will be shown to be common practice.

Many business owners would normally ferry their waste to communal collection points, while others would simply opt for the most convenient method of wastes disposal — indiscriminate dumping in nearby surroundings. It is common for some traders in riverine communities to dump their waste in lakes, creeks and rivers as this method of disposal appears to be the most convenient option available to them due to proximity. Often times, wastes disposed into water bodies contains a high percentage of putrescible materials, thereby altering the biological and chemical characteristics of water bodies. In addition, dumping wastes into water bodies increases the biological oxygen demand leading to a reducing of oxygen content in the river and posing threats to aquatic life (Nkwocha et al., 2011).

\subsection{Rational for the Current study}

The current study explores the wastes management strategies employed by small scale businesses in Yenagoa, the capital city of Bayelsa state, Nigeria. The aim of the study is to establish whether a link exists between the poor state of solid wastes management observed across the country and the types of wastes management practices adopted by businesses. It is suspected that the findings of the study will have wider applications beyond the immediate population where samples were drawn from. That is to say, if it is established that the types of management strategies adopted by businesses contributes to the general poor state of wastes management in the country, then by inference the types of management strategies adopted by householders, major companies and institutions across the country will have to change towards a more sustainable and environmentally friendly wastes management practices. This is because it has been proven that most small businesses and householders use similar wastes management practices.

\section{Methodology}

In order to provide a deep understanding and also generate high quality information and data, the current paper adopts a mixture of some aspects of quantitative and qualitative methods. This is necessary considering the fact that the research is intended to cover several aspects of waste management in Nigeria using Yenagoa as a case study area. The survey which was conducted between July and October, 2014 covered many streets and suburbs of Yenagoa. The technique adopted for the study involved the collection of both quantitative and qualitative data through the use of a questionnaire designed to capture data on the management practices of retailers in the city. The essence of using both qualitative and quantitative methods was necessitated by the fact that qualitative research methods deals principally with non-numerical data while quantitative methodsare used to capture numerical data. It is therefore appropriate for the current paper to adopt a mixed method approach of investigation.

Ezeah \& Robert (2013) reported that telephone and postal services in Nigeria are not as effective as those found in developed countries, hence they suggested the use of a door to door questionnaire administration. The present paper therefore employed a door to door style of questionnaire administration.

In addition to the questionnaire survey, the research included visual inspections of the refuse bins used at the business premises of the interviewees, and these observations were recorded. This inspection was necessary in order to ensure that only accurate information on wastes characterization was collected.

Since the researcher was unable to obtain a sampling frame for the study, a "multi stage cluster sampling" technique was employed. This technique allowed the researcher to purposefully pick some clusters and then develop individual sampling frame for each cluster before proceeding to collect sample using the sampling frame developed.

\section{Result}

Question 1- How do you dispose of your waste? 
Since most of the participants affirmed that their wastes are not collected directly from their premises during the pilot survey; and knowing that participants might have various methods of waste disposal. The survey therefore asked participants to state their methods of waste disposal.

It was revealed that of the 900 participants that took part in the study, about 946 responses were given instead of 900 responses. This is an indication that some participants used more than one method of waste disposal. The most popular response given by the respondents are; "I use the communal collection points to dispose my waste." This response represents $48.4 \%$ of all responses given, about $71 \%$ of the respondents gave this option. Similarly, $13.7 \%$ of the respondents confirmed that they sometimes dispose their wastes through dump sites or landfill. $14.2 \%$ of the respondents stated that they sometimes use random dumping as a means of waste disposal; this response represents $9.6 \%$ of all the responses. Another $14.6 \%$ of the respondents confirmed that they sometimes dispose their wastes on water bodies. Disposal on water bodies represents $9.9 \%$ of all the responses given. A further $22 \%$ of the participants dispose their wastes through open burning and $11.5 \%$ use other methods of wastes disposal.

Question 2-How do you store your waste?

When participants were asked about their mode of wastes storage, their responses revealed that retailers use multiple storage containers to store their wastes before disposal. The 900 participants provided about 3763 responses suggesting that some of the respondents uses over 3 methods of wastes storage. A breakdown of the responses shows that $19.7 \%$ of the participants use Bagco sack for wastes storage; this represents about $4.7 \%$ of all the responses given. $29.3 \%$ uses garri sack which account for about $7 \%$ of the responses received.61.1\% confirmed that they use Environmental basket/bucket for waste storage, this was the most popular container for waste storage among the participants, as this method make up about $14.6 \%$ of all the responses received. A further $29.6 \%$ of the respondents use pure water bag to store their wastes while $45.6 \%$ use black bin bag and $42.4 \%$ use cardboard boxes to store their wastes. In addition, $10.6 \%$ of the participants responded that they use other sack. $34.1 \%$ of use paint bucket and $35.2 \%$ use unwanted plastic buckets. $34.9 \%$ of the participants use other polythene bags while a further $10.6 \%$ of the respondents use other storage containers and another $43.7 \%$ uses rice sack.

This pattern of response is an indication that no specific wastes management strategy exist among retailers in respect to wastes storage. People store their wastes with whatever is available to store wastes at any point in time.

Question 3-What is the volume of your waste storage container

When participants were asked about the volume of their wastes bin, $9.1 \%$ of them confirmed that they use 10 litre storage containers to store their wastes while $0.4 \%$ uses 15 litres container. $35.9 \%$ of those who took part in the study use 20 litres containers for their waste storage while $0.6 \%$ uses 30 litres containers. A further $24.4 \%$ of the participants use 50 litres storage container and $29.6 \%$ use 80 litres container.

Most retailers appear to use 20,50 and 80 litre containers for wastes storage. The pace of business activities was suspected to be a major factor which dictates the volume of storage containers used by a business.

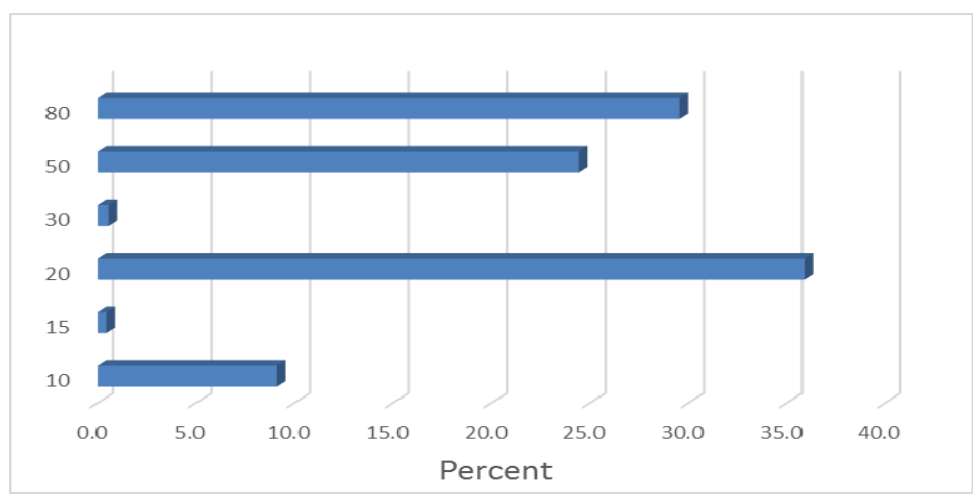

Figure 1. Volume of wastes storage containers 
Question 4-How frequently are your waste containers emptied?

One of the objectives of the research is to obtain as much details as possible in respect to the current wastes management practicesof businesses. Therefore, respondents were asked about the length of time (in days) that their wastes are kept before disposal.

Figure 2 presents the responses of the participants. According to the figure, $1.8 \%$ of the participants take between 1-3 days to dispose their wastes. $11.3 \%$ take between 4-6 days for them to dispose their wastes. $30.7 \%$ dispose of their wastes after about 7-9 days and $19.9 \%$ of the respondents take between 10-12 days to dispose their wastes. $7.6 \%$ takes between 13-15 days to dispose of their wastes and a further $20.6 \%$ dispose of their wastes between 16-18 days. 5.6\% of all those who took part in the study dispose of their wastes after storing them for between 19 and 21. Similarly, 1.6\%of the participants store their wastes for between 22 and 24 before disposal and $0.4 \%$ store their wastes for between 25 and 27 days before disposal. Furthermore, $0.7 \%$ of the respondents store their wastes for between 28 and 30 days before disposing their wastes. From the response, most of the participants dispose their wastes after about 9 days.

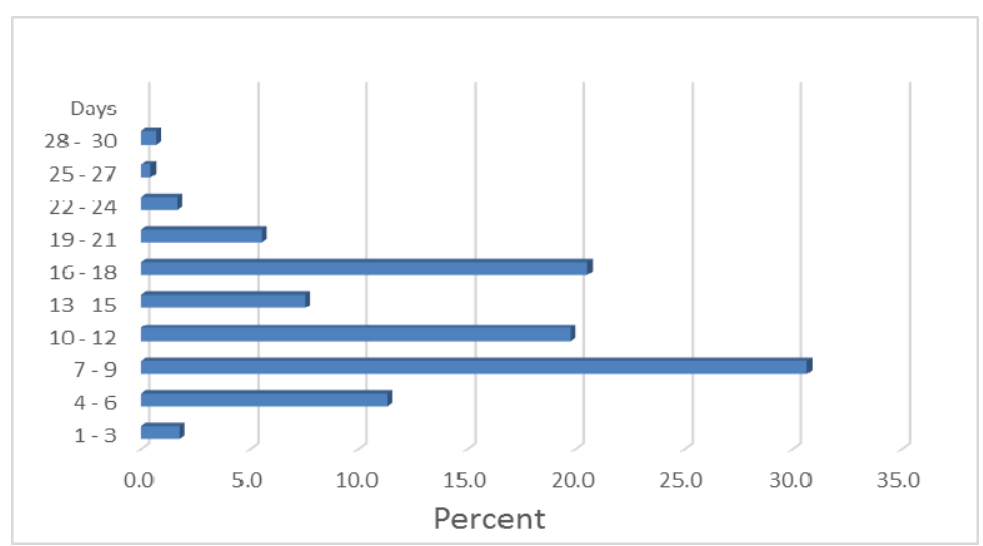

Figure 2. Frequency of wastes disposal

Statement 5-My wastes are collected by a third party from my premises for disposal

Participants were asked to state their position in relation to direct wastes collection from their businesses premises;

The responses of retailers showed that $90.6 \%$ of the participants do not have access to a door to door collection service. However, a small percentage of the participating businesses $(9.34 \%)$ have a door to door waste collection service available to them mostly through private arrangement with informal collectors.

A close examination of the responses showed that generally retailers in Yenagoa do not receive a door to door collection service from the government or indeed private organisations.

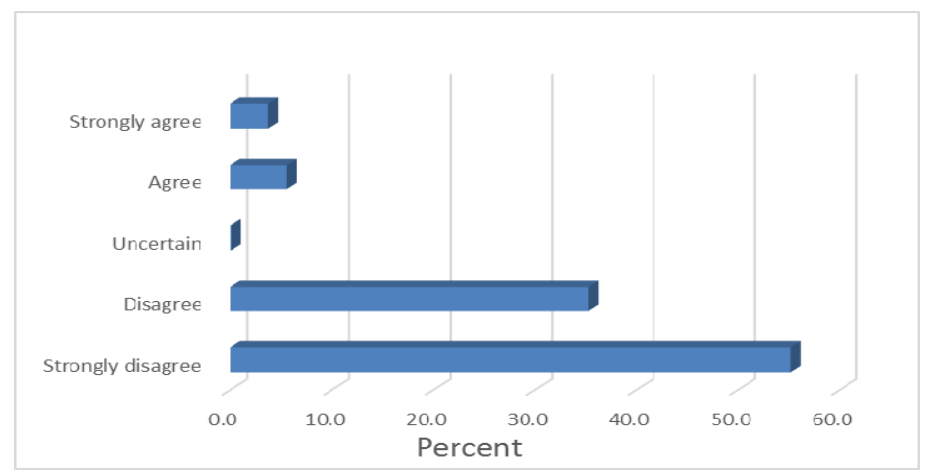

Figure 3. Third party wastes collection

Statement 6-A payment arrangement exists between my business and a private waste collector 
As a follow up to the previous statement, this statement aims to establish the payment arrangement in place between retailers and waste collectors (informal or formal). Participants were asked to respond to statement 6; the responses received showed that $89.89 \%$ of those who participated in the study disagree that there is a payment arrangement between their business and a waste collector while $10.11 \%$ agreed. This implies that majority of the participants do not have any arrangement in place for their wastes to be collected from their premises in exchange for payment.

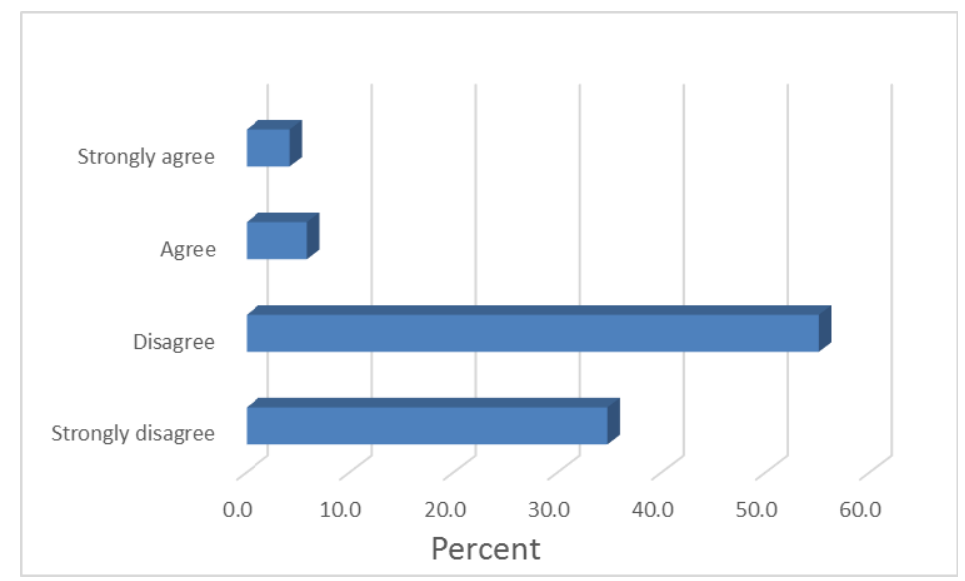

Figure 4. Payment for private wastes collection

Question 7-What tools/equipment are used for the collection of your wastes from your business premises by wastes collectors?

In order to fully understand how waste management works in Nigeria, and to gather adequate information on the mode of waste management practices. Participants were asked about the type of equipment used for the collection or removal of their wastes from their premises.

It can be observed that $1.9 \%$ of the participants confirmed that their wastes are collected with the aid of wheelbarrow; 0.3 with a pushcart, 0.6 with a baskets and $91.4 \%$ confirmed that their waste are not collected from their premises by the city authorities, waste management contractors or even by an informal collectors. About $5.8 \%$ of the remaining participants said their wastes are collected with the aid of other tools. From this information, majority of the respondent's wastes are not removed directly from their premises by third parties. Rather in many shops, retail workers were responsible for the evacuation of wastes from their business premises to disposal points.

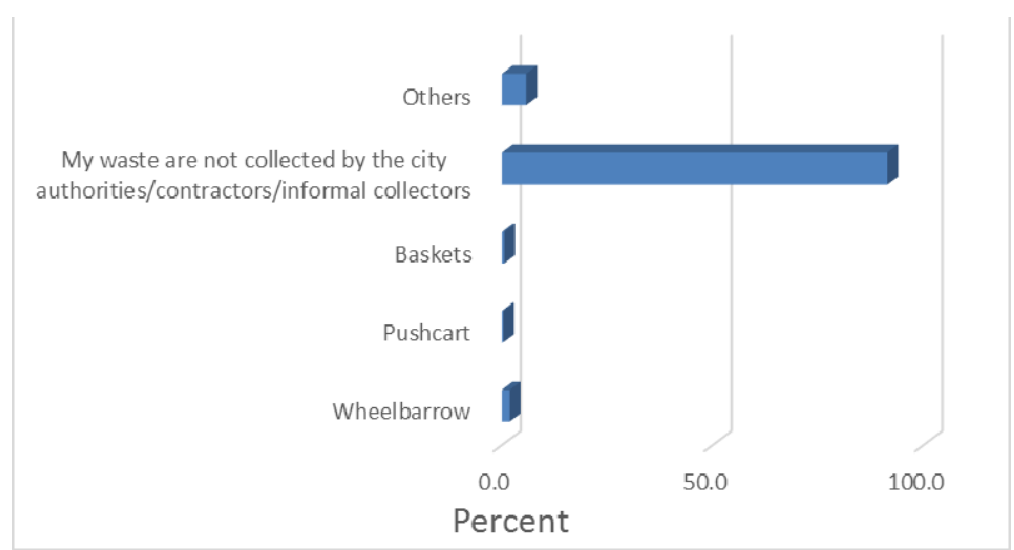

Figure 5. Equipment used for wastes collection 


\section{Discussion}

\subsection{Current Waste Management Practice amongst Retailers in Yenagoa}

Retailers were found to have similar wastes management routine. Many of the businesses usually have an appointed member of staff responsible for cleaning and tidying. This member of staff is the nominated individual responsible for wastes management issues. Every day before the commencement of business activities, the individual responsible for waste management will clean the store, the surrounding and gather wastes for storage. The stored wastes are then collected and disposed of by wastes collectors or a member of staff as soon as the container is full.

\subsubsection{Storage Pattern, Duration and Volume}

Retailers often store their wastes in-house or outside their stores. Various types of containers orbagsare used. Some retailers confirm that they use a combination of materials for storage. Details of the most commonly used containers are briefly described below:
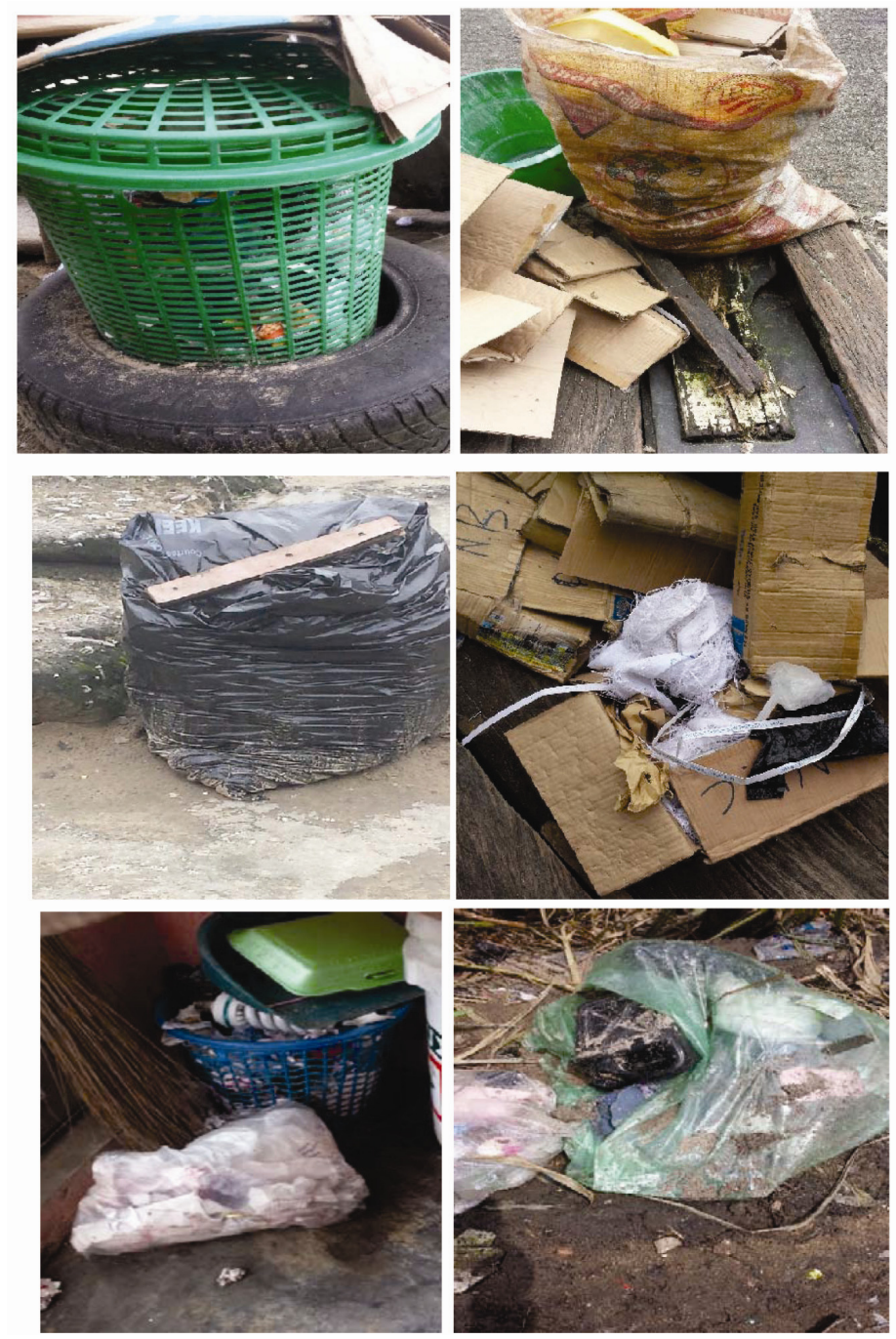

Figure 6. Waste storage pattern (author's field photograph)

\section{- Sack bags}

Retailers use different types of sacks for wastes storage. Some of the popularly used sacks include: Garri, rice, bagco among others. These sacks are packaging bags used for various products, many retailers use them for wastes storage due to their rigidity and ability to withstand pressure. On getting to the dump sites, retailers would empty the contents of the bags/sack on the dump site. Typically the sacks are used until it has been contaminated by putrescible materials or until they get torn. Some retailers use the sack bags only when they return from 
purchasing goods from wholesalers, using it only once and then discarding the bags together with the contents at disposal sites. A few other retailers simply dispose of such bags in the refuse bin without reusing them for wastes storage.

\section{- $\quad$ Polythene bags}

This is yet another popular wastes storage bag often used by retailers. In many cases, these bags are used as temporal storage bags for a few days before, they would normally be disposed alongside their contents. Some of the typical polythene bags used include: pure water bag, supermarkets bags, Dangote bags and a host of other small packaging bags. Most of these bags are mostly used once. Some are tough and withstands pressure, others are fragile. The bags are mostly disposed of with their contents. Some retailers confirm that they would normally keep bigger bags that come with goods from manufacturers so that they can be reused for wastes storage.

\section{- Cardboard boxes}

Many retailers use cardboard boxes to store their wastes at one point or another. Most goods purchased from suppliers come with cardboard boxes of various sizes. As soon as the products in the boxes are removed from the cardboard boxes, they are displayed in stores while the cardboard boxes are stored to be reused as temporal waste storage container. Most times the boxes are discarded along with their contents at disposal sites. Although it makes sense to reuse these boxes, the problem however that is they are fragile and susceptible to weather condition. Most retailers keep their wastes storage container outdoor during business hours, this exposes them to rain and water which damages the boxes. When retailers were asked about the possibility of the boxes getting wet from rain, they responded that during rains the boxes are removed and kept in store, beside the store or incorridors of their store. They added that since most of the contents are recyclable materials, it is not uncomfortable keeping them in stores during rains. Nonetheless, there were a few stores visited where wet/dissolved cardboard boxes were seen.

\section{- $\quad$ Plastic buckets}

Some of the common plastic buckets used for wastes storage by retailers include: paint buckets, disused household buckets, other plastic containers of various sizes. The practice of using buckets for wastes storage seems very popular among small businesses. Many of the plastic buckets have covers, particularly the paint bucket. Wastes materials are stored directed in the buckets without liners, the contents of the container are disposed while the buckets are returned to the stores. These types of containers are mostly used several times before they are discarded. A few retailers do empty the contents of the buckets into plastics bags before taking the bags away for disposal.

\section{- Black bin bags/Sanitation bags}

Bin bags are widely used for the storage of commercially generated wastes among businesses. In Yenagoa where the samples were drawn from, these bags are recommended by the wastes management authorities. Businesses are required to transfer their wastes into these bags before disposal so as to make collection easier. The bags are voluminous and are rigid than some of the other polythene bags used by businesses. The bags can either be used as bin liners with other containers or alone as storage bags.

\section{- $\quad$ Sanitation baskets}

These baskets are sold to retailers by the sanitation agency, many retailers complained that the agency sell the baskets forprices higher than the normal cost. It is possible that the baskets provide a source of extra revenue for the agency. These baskets would usually come with covers and they are suitable for many types of materials except fine materials. These baskets are the official containers recommended for wastes storage by the waste management agency in Yenagoa. The intention is for retailers to use black bags as liners rather than store wastes directly in the baskets.

\subsection{Wastes Collection}

Typically the collection of wastes generated by small businesses does not differ significantly from the collection pattern of householders. It was observed that the wastes management agency and their contractors does not provide kerbside and door to door collection of wastes for domestic, commercial and industrial premises. This is the trend in many Nigerian cities. 


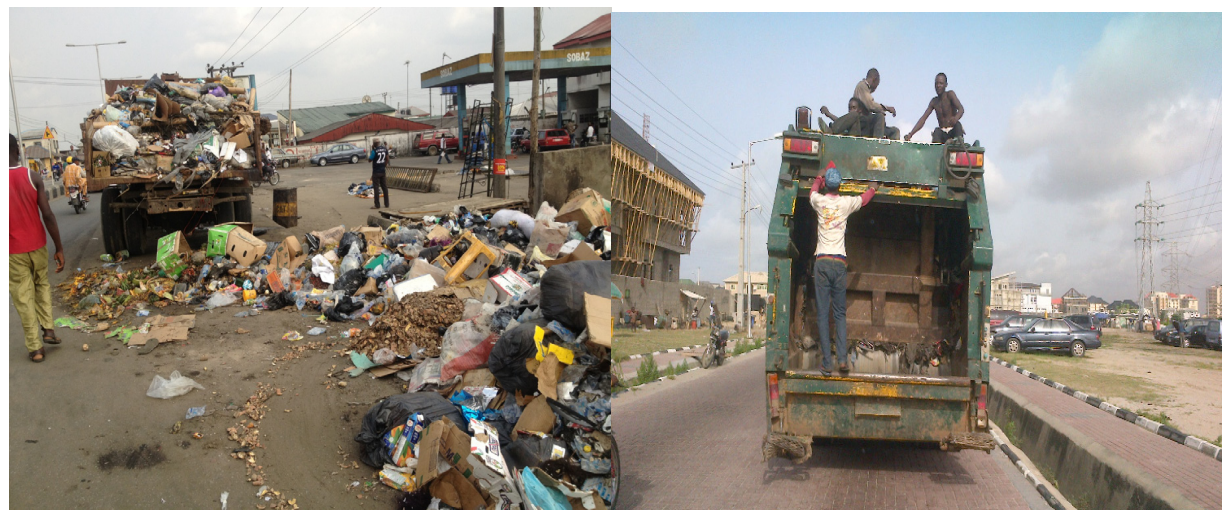

Figure 7. Typical wastes collection operation (Obasi, 2012; Onu et al., 2014)

Individual businesses are supposed to arrange for the collection of their wastes privately as are residential properties. Many stores confirm that their wastes are taken away for disposal by a member of staff mostly after working hours. A small number of businesses however affirmed that their wastes are collected by private collectors. These private collectors in some cases are members of the family who do not normally work for the business. These collectors would visit the business premises for the sole purpose of helping their relatives (business owner) to clean his/her business premises and also dispose of any wastes in storage containers. People in this category are mostly children or young people who may be children, siblings or extended family members of the business owners. Apart from this category of wastes collectors, the most popular wastes collectors after members of staff are informal wastes collectors. These informal collectors are people paid by businesses for the sole purpose of collecting wastes for disposal directly from business premises. Some retailers mentioned that informal wastes collectors are mostly employed by bigger businesses such as hotels, established eateries, small institutions and offices. Although not many retailers engage the services of people outside their businesses for wastes disposal, it was found that out of the 88 retailers who uses people outside their businesses to dispose wastes, $95.5 \%$ of them pay the wastes collectors. This confirms that most retailers who use private wastes collectors, engages the services of informal collectors.

Informal wastes collectors are not very popular in the sampled area-Yenagoa, unlike in cities like Lagos, Port Harcourt, Aba and Onitsha. The study found that most of the informal collectors use tools such as baskets, wheelbarrows, pushcart, amongst others.

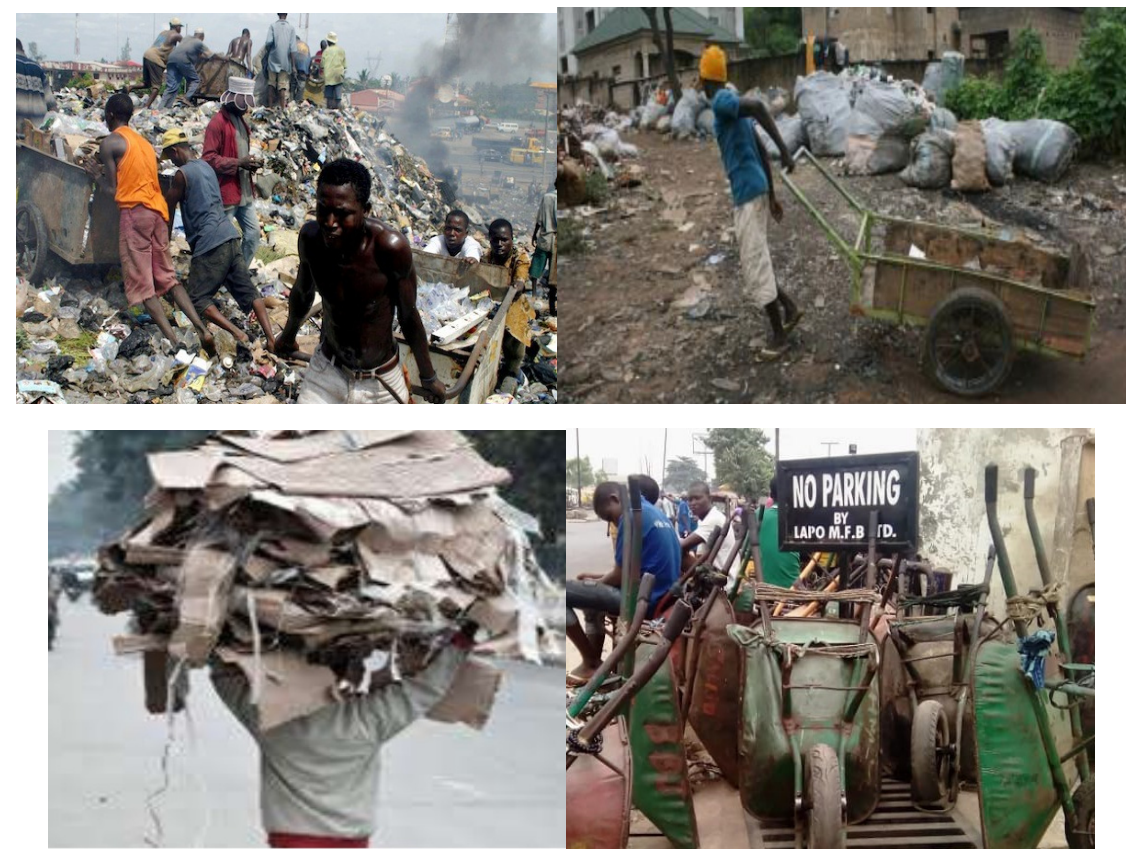

Figure 8. Methods of informal wastes collection (Adewole, n.d.; Hakeem, 2016; Rigasa, 2013; SweetCrude, 2014) 
There are issues associated with the use of third party individuals for wastes collection and disposal. When retailers were asked whether they know if the people they engage to dispose wastes actually dispose wastes on communal collection facilities, most businesses confirmed that they had no idea. A few others however confirm that there have been issues in the past where informal collectors dump wastes indiscriminately on unoccupied land, bushes and even uncompleted buildings. Nonetheless, this type of waste collection service provide a part time job for the people involved, many of them often engaged in multiple unskilled jobs. Most of the informal collectors are young people who usually live within the neighbourhood of the businesses that they work for as informal collectors. Therefore, they are easy to reach when their services are required. Businesses who have favourites among the collectors confirm that they usually call them on phone to inform them that their services are required. The pattern of collection is the same for retailers whose family members collect their wastes for disposal.

As the name imply, informal wastes collectors provide an informal service hence there is no regulation or enforcement to ensure that people who collect wastes for a fee disposes the wastes at the appropriate designated points. There is a possibility of illegal dumping due to the fact that it is an unregulated system. Nevertheless, it is an important method of wastes management which enables businesses to concentrate more on their business whilst providing part time employment for unemployed and unskilled residents.

\subsection{Methods of Wastes Disposal}

Just as wastes are stored in different containers, the disposal pattern among retailers are numerous. Several factors drive the wastes disposal pattern of small businesses. However, convenience seems to be one of the most important factors.

\section{- Wastes burning}

This is a common disposal method by many businesses in the study area. Burning of wastes involves the act of setting fire to wastes materials. The main method of burning was found to be open burning on the floor, usually at the back of the store. Materials are gathered at the back of the stores and then set alight. Occasionally when a higher temperature is required, kerosene is used to aid the burning. The liquid is sprinkled on the materials before using a matchstick to start the fire or burning process. Where a reasonable temperature is needed, a good quantity of kerosene is used depending on the nature of materials to be burned. Where the wastes consist mainly of recyclables such as paper, cardboard, polythene and plastics, the materials are simply set alight without the use of kerosene. This is because such materials are easily combustible. In many cases however, wastes are mixed with readily combustible and non-combustible materials before burning.

"I burn my wastes together because some easily combustible materials acts as fuel, the fuel they generate increases the intensity of heat to help the slow burning materials burn easily"-store owner.

All types of wastes materials are burned including putrescible. The ash from the fire is bagged or packed for disposal at a later date until the storage container or bag is filled to capacity. When it is time for disposal, both burned and unburned wastes are mixed together for disposal. In some cases, the ash is left in the area where the burning took place with the hope that it will be washed away as run off-mostlyduring the raining seasons. Where they are not washed away by rain, they are collected and disposed of during the compulsory monthly sanitation days when people are expected to keep their environment clean.

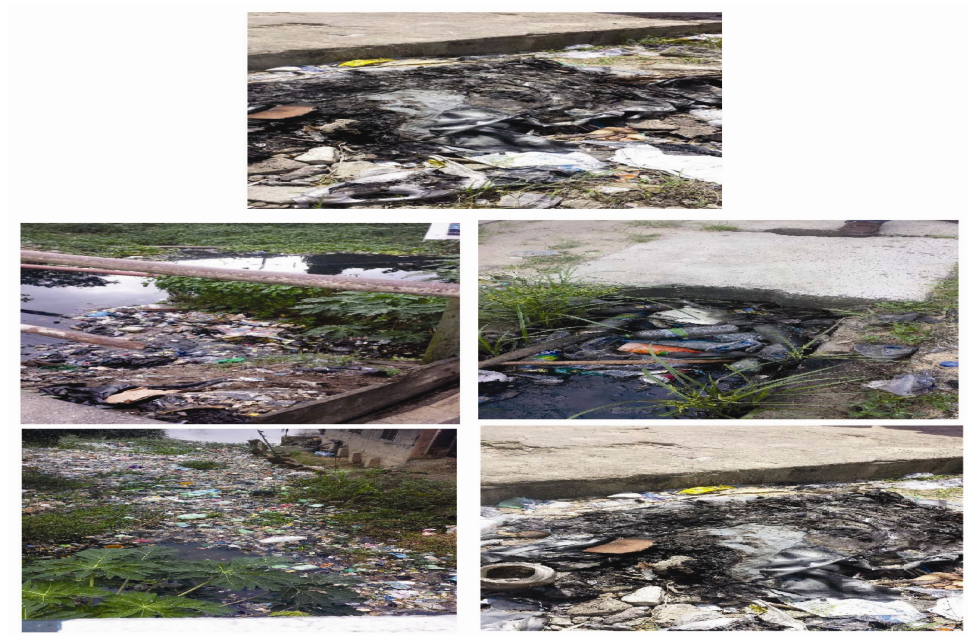

Figure 9. Wastes disposal pattern (Author's field photograph) 
Burning of wastesis an easy method of wastes disposal to businesses involved in the practice,these sets of businesses argued that the practice afford them the opportunity of disposing their wastes without having to leave their business premises. In addition, it is relatively cheap as no money is paid for disposal.

\section{- Dumping on water bodies}

Going by the responses received from participants, dumping on water bodies is not a popular method of disposal among businesses. Nevertheless, it is still a method of wastes disposal among a small fraction of businesses. Yenagoa being aNiger Delta city is dotted with rivers, lakes, lagoons and creeks. This provides a huge opportunity for small businesses to dispose their wastes on water bodies. Retailers who engage in dumping on water bodies mostly ply their trades along or beside water bodies.

"I do dispose wastes materials into nearby creeks. However, I do not think that the practice is harmful becausewater from the creeks empties into Yenagoa river carrying most of the debris along as it flows"-retailer.

It is common to have a lake at the backyard of a store, across the road from the store or at a stone throw from the store. Due to these proximities, water bodies provide ample opportunities for wastes dumping. Since some of these water bodies are not stagnant, wastes are carried away by currents as the water flows towards a larger water body.

Different types of wastes are dumped in these water bodies from food wastes, fabrics, tins, plastics, polythene bags to cardboard boxes. However, tins, polythene bags and plastic materials seem to float on the creeks for longer. This is because the rate of flow of some of the water bodies is low and the thick vegetation around these water bodies impede the flow of these materials into the river from where they are supposed to be washed into the sea. Denser materials - food, solids usually sink below the surface. Hence look around some of the inland water bodies reveal mostly less dense materials at the surface of water bodies.

Officially businesses are not allowed to dispose wastes on water bodies. Although, this is hardly enforced. Surprisingly, a retailer shared his experience with the research team.

"Yes, I throw materials into the water channel nearby just like every other person. However, passer-bys are the major offenders. Here weonly dispose wastes materials into the channel during rains because the materials are usually carried away with run offs into nearby creeks and rivers"--shop worker.

Occasionally the wastes management agency and their contractors do go round the city on street cleaning exercise. However, debris is left to flow freely on water bodies. The lack of attention to the filth along water channels suggest that city authorities are not concerned about ridding the inland water bodies of debris.

\section{- $\quad$ Dump sites}

Many retailers confirmed that they use this option for the disposal of their wastes. There are so many illegal dump sites all around the city. The dump sites are places where residents and businesses dump their wastes in many cases without authorization from the wastes management bodies. Some of the dump sites in Yenagoa are mostly in abandon lands, properties bushes and road side. The dump sites usually start with one or two residents dumping wastes at a particular spots. Such spots are easily noticed by other residents who will also decide to dump their wastes at the spot rather than walk a few meters or kilometres to the authorised disposal points. Before long a new dump site would be formed where people will take their wastes to for disposal. After weeks or months, the attention of the wastes management agency will be drawn to the new dump site, the agency will then proceed to collect the wastes for disposal. Residents will keep using the same spots and the wastes management agency will keep collecting the wastes until someone possibly living within the area or the owner of the land makes a complaint. The wastes will then be cleared by the agency and a signpost erected to say that people will be fined or prosecuted for disposing their wastes at that spot.

Some retailers affirm that they dump their wastes on dump sites located within a few minutes' walk from their stores. Others confirmed that they pack their wastes properly after business hours so as to dispose them on their way home. Although wastes disposal on dumpsites are frowned upon by city officials, the practice was found to be one of the popular method of wastes disposal among retailers. Apart from the retailers themselves, those who collect wastes on their behalf (informal collectors) and relatives also use dumpsites for wastes disposal. The wastes thrown at these sites are usually a combination of different materials. A few wastes scavengers (not popular in the area of study) often engage in wastes picking activities in selected dumpsites. 


\section{- Communal collection points}

Communal collection points are the most commonly used method of wastes disposal among retailers. This method of disposal is also the official method of wastes disposal in the city. As the name suggest, communal collection points are disposal points for the collective use of the community. In Yenagoa, businesses and residential properties use these points for their wastes disposal.

The collection points are provided by the wastes management agency in many locations across the city. Wastes collected by members of staff of retail stores, informal collectors and family members of store owners are disposed of at these points. Depending on the location of a store, the collection points might be a few metres across the road or several miles away. The location of the collection points is irregular, as the facilities are sited without proper planning. It is suspected that other factors may be responsible for the siting of the facilities rather than distance from businesses and residential buildings. There are no prior arrangements for collection points to be located every 1, 2 or 3 miles from each other throughout the city. Perhaps availability of space might be a factor for the location of communal collection points. Hence, where the space is available a provision is made for collection point to be sited in the location. This irregular pattern has its disadvantages as shown later in this paper.

Two types of wastes collection points exist in the city. The oldest system is a system where big/small skips are provided at designated points whereas the recent system are small concrete structures built at different areas in the city. The new facilities (collection point) are shown in the pictures below. It can be observed that the concrete structures are not a well thought out structures as litters are easily blown or carried away from the communal disposal points by wind and rain.

Nevertheless, the concrete structures seem to be replacing the traditional methods of proving big metallic skip for wastes disposal. Businesses and other users are expected to dump wastes on specified days-Mondays, Wednesdays and Fridays within a five hour period. This, it seems is to ensure that wastes are disposed of close to the collection days to avoid overflow and litters lying around for several days. The idea behind the concrete structures is that only wastes wrapped in black bags popularly referred to as sanitation bags should be dumped at the spots.
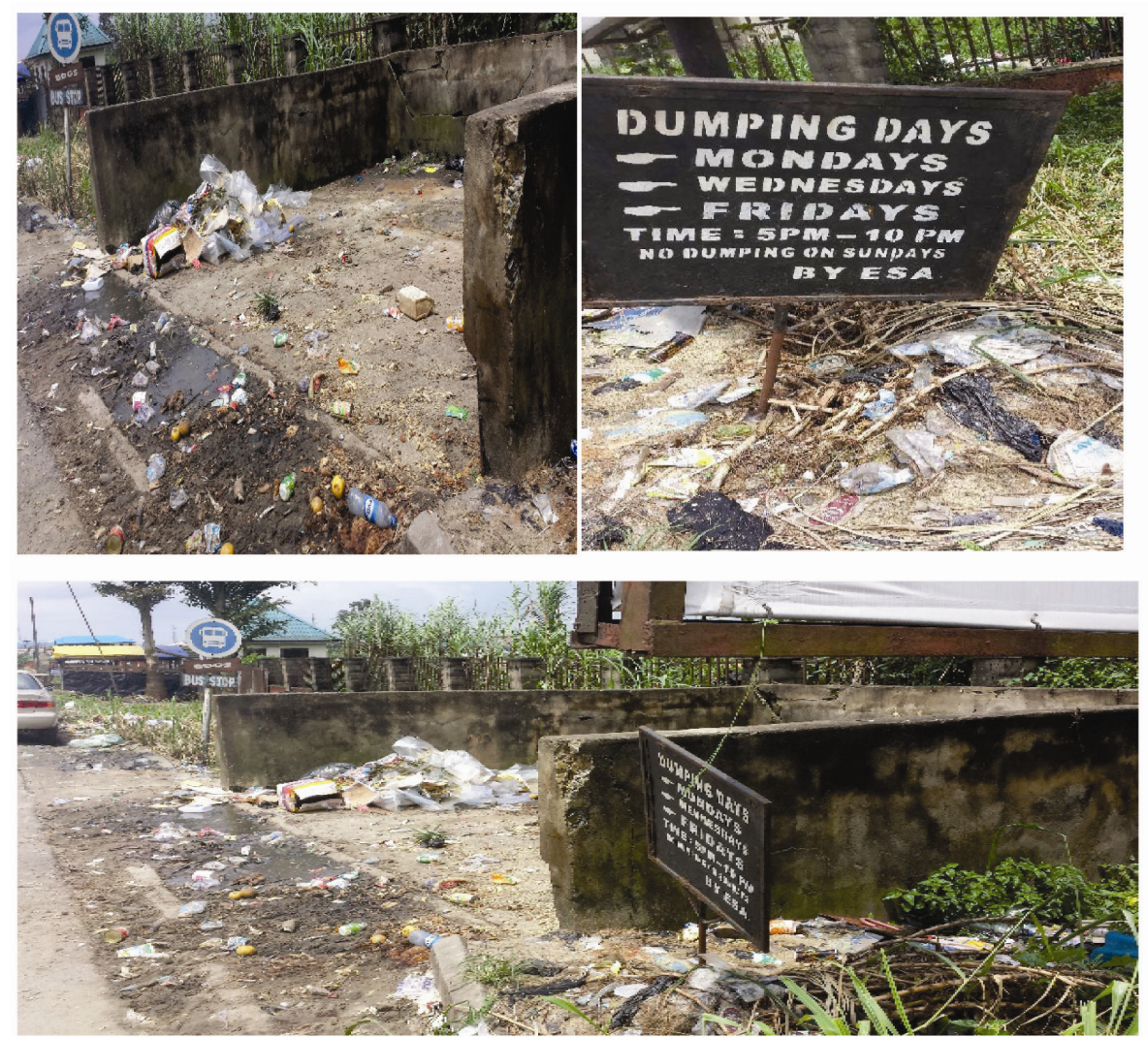

Figure 10. Communal disposal point (Author's field photograph) 
The bags are sold in many supermarkets across the city for 350 Naira per roll. The intention of using the bags is to allow the Bayelsa State wastes management agency or their contractors to collect the neatly wrapped wastes from the communal collection points by simply picking up the wastes and transferring them into the collection trucks. This is however not the case as some retailers confided in the research team that they do not use the black bags to wrap their wastes before disposal. Some of the retailers argue that the bags are too expensive and that they should be allowed to use other types of bags for their wastes disposal. As a result some retailers use other types of bag to pack their wastes while a few others do not. Hence, the contractors often use baskets and shovels to gather the wastes and then transfer them into the waiting trucks.

It is very likely that most retailers can afford to buy the bags for wastes disposal. However, many of them are used to the older method of dumping wastes directly onto skips without having to bag them. In addition, the environmental culture of businesses was found to be very poor. Hence, retailers are reluctant to spend anything beyond the compulsory sanitation fees paid to the wastes management authorities.

The older method of wastes collection in Yenagoa involves the use of huge metal skips. These skips are located at strategic points across the city. Businesses and householders were not required to pre-pack or wrap their wastes in a bag prior to disposal. Wastes were simply thrown in the skips until filled, after which the wastes management agency or contractors collect the wastes by exchanging an empty skip for the filled skip. The skip is taken to the central dumpsite at Tombia where the contents are offloaded onto the dumpsite. Many of the retailers reckon that the skip system was a lot better as wastes are transferred directly onto skips from the storage containers. This skip system does not require people to dispose wastes on particular days.

\section{- Random dumping of wastes}

It is known that people do randomly dispose wastes in the environment. However, the openness of retailers engaged in the practice was not expected since it is well known that indiscriminate dumping of wastes is illegal. Most businesses involved in the practice argued that random dumping of wastes was not their main mode of wastes disposal. Rather it is a practice used alongside other disposal practices. For instance a retailer may have a storage bin for the storage of wastes generated directly from business activities while wastes collected during the sweeping or cleaning of surrounding areas are simply thrown into nearby bush across the road. They may also be packed in a separate polythene bag and taken to an isolated area in the surrounding for disposal. This practice differs from disposal on dump site in that, those involve in disposal at dumpsite take wastes to refuse dumps for disposal rather than discarding materials at isolated areas or bush paths.

On further enquiry on why they dispose their wastes indiscriminately, many retailers gave similar excuses pointing to the fact that wastes from the surrounding areas are usually wetter, damp, diverse in characteristics and dirtier than wastes generated from their stores. To them therefore, it makes sense to pack such wastes and dispose them in surrounding areas after sweeping instead of storing them in the general wastes storage container. The diverse nature of the wastes from surrounding areas is usually due to wind, run off from rain, customers and passer-by's discarding materials randomly. These surrounding wastes are hardly stored, majority of the time, they are discarded almost immediately after sweeping. A few stores however store them outside the store in small polythene bags before disposing them on their way home.

This pattern is particularly true for some shops located in areas where only the motor roads are tarred whiles the immediate areas surrounding the stores are unpaved. In such areas wastes in the surrounding are usually mixed or contaminated with earth and fines, making them more difficult to handle. For retailers who are not too keen on environmental issues, it might be easier for them to discard these wastes via any means so that their business surroundings can be clean for customers.

As the research involves visual inspection of stored refuse bin, upon enquiry of the storage bins in a few stores, it was found that no wastes storage bin was kept by a few stores. This is a signal that such stores were actively dumping their wastes indiscriminately, possibly within a few meters from their stores after sweeping or tyding up. One retailers explanation sums up his reason for not having a wastes bin in store.

"I sell mainly clothes, shoes, handbags, wristwatches and other fashion accessories so I generate little or no wastes. Hence, I don't have a waste storage container"-store owner.

"The only waste we generate here are mainly earth materials from customer's shoes, on sweeping the store, we normally discard the earth materials outside in the environment-store worker.

Like most other business premises, these stores without storage bins are kept clean and tidy. Customers come and go, it is therefore difficult to believe that these businesses do not generate wastes. Retailers often buy goods from suppliers, these goods in most cases come with packaging, also most retailers spend a minimum of about 8 
hours a day in their shops, others even sell product late into the night. These activities often result to at least a small volume of wastes which ordinarily should be stored and disposed of. Unavailability of storage bins means that on sweeping of the store or at least the premises in the morning, the wastes are immediately disposed of.

\section{Conclusion and Recommendations}

The research investigates waste management practices among small businesses in Nigeria with samples collected from Yenagoa. The essence of the study was to determine whether a relationship exist between the poor states of wastes management in the country and the wastes management practices adopted by businesses. From investigation, it is clear that the wastes management practices of businesses are far from being environmentally sustainable. Businesses were found to use inappropriate wastes storage containers and bags for storage. This pattern of storage encourages the spread of diseases such as Lassa fever amongst others, as rodents and other vermin thrives in dirty environment. Some of the containers used regularly spills their contents into the environment due to their fragile characteristics. No uniform pattern of wastes disposal or collection was found among businesses. Some businesses engage the services of their relatives for wastes collection and disposal, someengage paid informal collectors while others rely on members of staff to collect and dispose wastes. It was found that some of the informal collectors employed to dispose wastes occasionally dump their wastes illegally in nearby surroundings thereby contributing to environmental pollution.

Various methods of wastes disposal practices were observed among businesses including burning, dumping on water bodies, communal collection points, indiscriminate dumping by the road side, on abandon land, properties, bushes and known dumpsites. These practices contribute to air, land and water pollution. They also reduce the biodiversity of the ecosystem and negatively affect the quality of life of poor residents who depend on agriculture and fishing. Some poor residents also depend on traditional wells as well as rivers and creeks for drinking water. Hence, there is no doubt that the current wastes management practices of businesses affect residents and members of the public.

Without a doubt it can be concluded that the wastes management practices of small scale businesses contribute immensely to the general poor state of wastes management reported in many Nigerian cities. Therefore, government and wastes management agencies in the country must develop specific policies and legislations aimed at addressing the handling of wastes generated by commercial activities. As much as possible, businesses must be encouraged to form small organizations among themselves with the sole aim of encouraging members to embrace positive environmental practices. As a form of encouragement, government should adopt the use of incentives to lure businesses into adopting environmentally friendly wastes management practices. Where possible, infrastructures should be made available to encourage recycling among businesses, for instance provision of recycling bank within close proximity to businesses. Most importantly wastes and environmental management policies should be policed to ensure that businesses abide by guidelines and regulations.

\section{References}

Abel, A. (2007). An analysis of solid waste generation in a traditional African city: the example of Ogbomoso, Nigeria. Environment and Urbanization, 19(2), 527-537. https://doi.org/10.1177/0956247807082834

Adewole, A. T. (2009). Waste management towards sustainable development in Nigeria: A case study of Lagos state. International Ngo Journal, 4, 173-179.

Adewole, T. (n. d.). Communal/informal Sector Participation in the Waste Management Industry. Retrieved from http://www.lawma.gov.ng/presentation/ipla/Informal\%20Sector\%20Participation\%20in\%20Waste\%20Mgt \%20-\%20Recyclepoints\%20Nig.\%20Ltd.pdf

Afon, A. O. (2007). Informal sector initiative in the primary sub-system of urban solid waste management in Lagos, Nigeria. Habitat International, 31(2), 193-204. https://doi.org/10.1016/j.habitatint.2007.02.007

Afon, A. O., \& Okewole, A. (2007). Estimating the quantity of solid waste generation in Oyo, Nigeria. Waste Management \& Research the Journal of the International Solid Wastes \& Public Cleansing Association Iswa, 25(4), 371-379. https://doi.org/10.1177/0734242X07078286

Afun, S. (2009). Government Regulations and Legislations Will Ensure Sustainable Waste Management in Nigeria. Retrieved from http://www.iswa.org/uploads/tx_iswaknowledgebase/le_2009_2-357.pdf

Agunwamba, J. C. (1998). Solid waste management in Nigeria: problems and issues. Environ. Environmental Management, 22(6), 849-856. https://doi.org/10.1007/s002679900152 
Hakeem, O. (2016). Exclusive: How truck pushers struggle everyday to survive. Naijcom—Niger. News. Retrieved from https://www.naij.com/752234-exclusive-truck-pushers-struggle-everyday-survive-lagos-photos.html

Nabegu, A. B. (2010). An analysis of municipal solid waste in Kano Metropolis, Nigeria. Journal Hum. Ecol., 31(2), 111-119.

Nkwocha, E. E., Pat-Mbano, E. C., \& Nnaji, A. (2011). Effect of Solid Waste Dump on River Water Quality: A Paradigm in a Nigerian Tropical Environment. Retrieved from $\mathrm{http}: / /$ www.scienceandnature.org/IJSN_Vol2(3)S2011/IJSN-VOL2(3)-12.pdf

Obasi, E. (2012). Green jobs in Nigeria: Imperatives for Vision 20-2020. Prem. Times Niger.

Onu, B., Surendran, S. S., \& Price, T. (2014). Impact of Inadequate Urban Planning on Municipal Solid Waste Management in the Niger Delta Region of Nigeria. https://doi.org/10.5539/jsd.v7n6p27

Rahji, M. A. Y., \& Oloruntoba, E. O. (2009). Determinants of households' willingness-to-pay for private solid waste management services in Ibadan, Nigeria. Waste Management \& Research the Journal of the International Solid Wastes \& Public Cleansing Association Iswa, 27(10), 961-965. https://doi.org/10.1177/0734242X09103824

Rigasa, Y. A. (2013). Waste Management Services: A Strategy for the Integration of "Almajiri” into Current Waste Management Action Plans of Urban Centres in Northern Nigeria.

Sweet Crude. (2014). Electricity supply from refuse dump. Sweet Crude Reports.

Uwadiegwu, B. O., \& Chukwu, K. E. (2013). Strategies for Effective Urban Solid Waste Management in Nigeria. European Scientific Journal. Retrieved from http://eujournal.org/index.php/esj/article/view/896

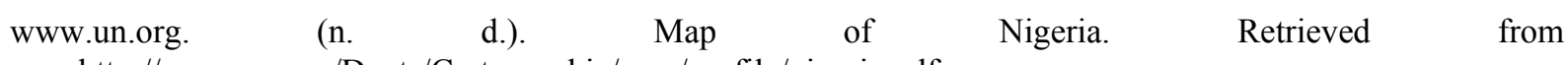
http://www.un.org/Depts/Cartographic/map/profile/nigeria.pdf

\section{Copyrights}

Copyright for this article is retained by the author(s), with first publication rights granted to the journal.

This is an open-access article distributed under the terms and conditions of the Creative Commons Attribution license (http://creativecommons.org/licenses/by/4.0/). 